\title{
PENINGKATAN KEMAMPUAN PEDAGOGIK TENAGA PENGAJAR PAUD DALAM UPAYA PEMBERDAYAAN MELALUI KETERAMPILAN LITERASI DIGITAL DI WILAYAH KOTA BOGOR
}

\author{
Henny Suharyati ${ }^{1}$, Yuyun Elizabeth Patras ${ }^{1}$, Mulyati ${ }^{1}$ \\ ${ }^{1}$ Universitas Pakuan, Jalan Pakuan Bogor \\ Email: henny.suharyati@unpak.ac.id
}

\begin{abstract}
Abstrak
Peningkatan daya saing di bidang pendidikan anak usia dini (PAUD) dikembangkan karena bidang ini menjadi salah satu pilar strategi nasional dalam nawacita pemerintah. Tantangan pendidikan di era edukasional 4.0 sangat besar terutama dalam meningkatkan daya saing bangsa. Upaya dilakukan dengan peningkatan kompetensi pedagogik guru dan keterkaitannya dengan literasi digital yang dihadapi ketika guru akan mengikuti Ujian Kompetensi Guru, pengisian data peserta didik secara online, pengisian borang akreditasi, pembuatan media pembelajaran yang inovatif. Pembinaan sudah banyak dilakukan baik untuk pembinaan manajemen, kompetensi guru, parenting dan penelurusan bakat anak didik. Hal ini menjadi masalah baru yang perlu dipetakan dalam sistem yang akan dibangun berupa peningkatan kompetensi pedagogik guru dalam upaya pemberdayaan kemampuan literasi digital. Kegiatan tahap awal akan diintegrasikan pada pelatihan-pelatihan dan pendampingan dalam mengerjakan kegiatan yang berkaitan dengan teknogi sehingga diperoleh luaran ketrampilan literasi digital para tenaga pengajar PAUD. Hasil yang diperoleh adalah peningkatan kemampuan guru dalam mengakses program yang terkait dengan digitalisasi yang kemudian dikembangkan dalam bentuk kreativitas guru mendesain bahan ajar berbasis multimedia. Manfaat yang diperoleh adalah peningkatan kompetensi digital guru yang juga akan meningkatkan kualitas mutu lulusan.
\end{abstract}

Kata kunci: Peningkatan daya saing PAUD, kompetensi pedagogik guru, literasi digital

\section{PENDAHULUAN}

Peningkatan daya saing di pendidikan anak usia dini (PAUD) banyak dikembangkan karena bidang ini menjadi salah satu pilar strategi nasional dalam nawacita pemerintah. Tantangan pendidikan di era edukasional 4.0 sangat besar terutama dalam meningkatkan daya saing bangsa. Penelitian tentang peranan kepemimpinan transformasional, budaya organisasi dan motivasi kerja guru dinilai penting dalam peningkatan inovasi guru Paud. (Suharyati, 2015). Beberapa penelitian lain banyak dilakukan dan salah satunya adalah 
DIFUSI

Volume 2, No.2 Juli 2019

BCCT (Beyond Centre and Circle Time) yaitu pendekatan pembelajaran melalui sentra dan lingkaran yang dilaksanakan belajar sambil bermain. Pentingnya pengembangan model manajemen strategik efektif dinilai dapat mengatasi permasalahan yang kompleks di sekolah dan terutama peran kepala sekolah dalam menjalankan strategi sekolah. Sekolah harus memiliki relevansi manajemen dengan pendekatan pembelajaran yang diterapkan berbasis BCCT, yang dipaparkan meliputi: sistem aktivitas pendidikan, sistem fasilitas pendidikan, dan sistem operasi pendidikan. Sistem aktivitas pendidikan mencakup aktivitas perencanaan kurikulum, sumber daya manusia, strategi program kerja, komunitas sekolah, pelatihan, pelayanan, dan evaluasi (Rindaningsih, 2012). Beberapa penelitian lainnya merekomendasikan agar guru PAUD dapat terus meningkatkan kemampuannya mengembangkan kompetensinya dengan cara melanjutkan pendidikan atau mengikuti pelatihan atau seminar yang dapat meningkatkan kompetensi dan motivasinya (Nugraha, 2017).

Jika potensi guru Paud Gandaria sangat besar namun tidak dibarengi dengan kemampuan pedagogik guru salah satunya memiliki ketrampilan literasi digital yang baik, maka solusi yang dapat ditawarkan adalah mengusulkan peningkatan kemampuan pedagogik tenaga pengajar PAUD dengan cara pemberdayaan ketrampilan literasi digital. Modal dasar pengelola, guru dan siswa adalah rasa percaya diri yang kuat dan kemampuan berdaya saing dengan PAUD lainnya. Rasa percaya diri membangun sikap mandiri, inovatif dan tangguh dari warga sekolah dan melahirkan kekuatan untuk berjuang dan bersaing di tingkat regional dan nasional. Oleh karena itu pada kegiatan Program Kemitraan Masyarakat ini mengajukan strategi peningkatan kompetensi pedagogik guru dengan pelatihan IPTEK dan pembuatan desain media pembelajaran yang kreatif dan inovatif, strategi pembelajaran berbasis pemecahan masalah meliputi literasi baca tulis, warna dan bentuk dikemas dalam ragam multi media. Aspek peningkatan literasi digital guru dengan yang berkelanjutan dan berkesinambungan diharapkan akan terpenuhi melalui kegiatan pelatihan Uji Kompetensi Guru (UKG), sistem akreditasi dan pengisian dapodik online.

\section{MATERI DAN METODE}

\section{Pelatihan Uji Kompetensi Guru (UKG) Online.}

Pelaksanaan pelatihan difokuskan pada cara masuk UKG online dan latihan mengisi soal-soal yang dilaksanakan di Laboratorium Komputer Fakultas MIPA Universitas Pakuan. Kegiatan pelatihan dilaksanakan setiap minggu mulai pukul 11.30-15.00. Tahap awal pelatihan mengulas tata cara masuk ke sistem Uji Kompetensi Guru online. Pelaksanaan pelatihan dilaksanakan dengan praktik langsung yaitu peserta diwajibkan untuk mengisi soal-soal UKG. Kegiatan praktek langsung ini dilakukan secara berkelompok, dan didampingi oleh tim LPPM. Evaluasi sebagai bagian dari tahap akhir ditujukan sebagai indikator keberhasilan pelatihan. Evaluasi dilakukan dalam bentuk evaluasi jangka pendek di kelas selama pelatihan berlang- 
DIFUSI

Volume 2, No.2 Juli 2019

sung dan dilanjutkan dengan memberikan pengayaan berupa tugas pelatihan bagi peserta menjawab soal-soal. Evaluasi berikutnya tim LPPM membuat FGD (Focus Group Discussion) dengan agenda presentasi dari peserta pelatihan untuk menyampaikan hasilnya dengan mengundang Himpaudi dan Gugus Paud Bogor Utara.

\section{Pelatihan Pengisian dan Sinkro- nisasi Dapodik Online.}

Pelaksanaan pelatihan akan difokuskan pada cara mengisi data peserta didik dalam format Excel yang dilaksanakan di Laboratorium Komputer Fakultas MIPA. Pelatihan dilanjutkan dengan pengisian data peserta didik terbaru. Kegiatan pelatihan akan dilaksanakan setiap minggu mulai pukul 11.30-15.00. Pelatihan tahap awal mengulas tata cara masuk mengunggah template Dapodik yang terbaru. Pada saat praktik langsung, peserta diwajibkan mengisi data peserta didik lama dan terbaru. Tim LPPM melakukan pendampingan pada saat kegiatan observasi langsung ini. Evaluasi tahap akhir dilakukan untuk mengukur indikator keberhasilan pelatihan. Tahapan evaluasi pada pelatihan ini berupa evaluasi jangka pendek dilakukan di kelas dan dilanjutkan dengan memberikan pengayaan dalam bentuk tugas pelatihan bagi setiap peserta. Evaluasi berikutnya dilakukan dalam jangka waktu setiap minggu.

\section{Pelatihan Pembuatan Borang Akreditasi Online}

Tempat dan waktu pelaksanaan pelatihan dijadwalkan sesuai dengan kedua pelatihan sebelumnya. Tempat pelatihan masih berlangsung di Laboratorium Komputer Fakultas Mipa Universitas Pakuan. Waktu pelaksanaan disesuaikan dengan jadwal mengajar guru-guru. Adapun materi awal pelatihan menjelaskan 8 standar penilaian borang akreditasi. Penerapan ipteks dilakukan dengan metode kombinasi yaitu dngan tutorial dan praktik langsung. Pertama peserta dibagi menjadi 4 kelompok dan setiap kelompok mengerjakan 2 standar. Pelatihan browsing (mencari) materi utama, literatur maupun materi pendukung isian borang dengan memanfaatkan fasilitas internet diberikan untuk menguatkan kompetensi guru dalam pemberdayaan literasi digital.

Setelah pelatihan, Tim pelaksana abdimas melakukan evaluasi pre test dan post test untuk mengukur indikator keberhasilan pelatihan. Evaluasi jangka pendek yang dilakukan di kelas selama pelatihan berlangsung kemudian pengayaan berupa tugas pelatihan bagi peserta agar berlatih mandiri untuk melengkapi dan menyempurnakan Borang Akreditasi. Evaluasi jangka panjang dilakukan melalui proses presentasi progres hasil pengisian borangnya. Pada tahap akhir setiap kelompok peserta diminta presentasi borang yang sudah dikerjakannya. Masukan yang bersifat konstruktif akan diadopsi untuk revisi borang tersebut.

\section{Pelatihan Pembuatan Desain Media Pembelajaran Kreatif dan Inovatif.}

Pelaksanaan awal pelatihan dilakukan di kelas Paud Gandaria di Kelurahan Tegal Gundil. Waktu kegiatan pelatihan dilaksanakan selesai jadwal guru mengajar. 
DIFUSI

Volume 2, No.2 Juli 2019

Metoda pelatihan penerapan ipteks dilaksanakan dengan kombinasi tutorial $30 \%$ dan praktik langsung $70 \%$. Pembelajaran desain multimedia memerlukan pelatihan yang banyak. Pengaturan awal dengan pembagian kelompok peserta. Praktik langsung lebih menggunakan komputer untuk setiap peserta.

Evaluasi dilakukan secara bertahap untuk mengukur indikator keberhasilan pelatihan. Evaluasi jangka pendek dilakukan saat pembelajaran di dalam kelas selama pelatihan berlangsung dan pengayaan berupa tugas pelatihan bagi peserta diberikan agar peserta berlatih mandiri membuat dan menyempurnakan proses rancang bangun media pembelajaran. Evaluasi mingguan dilaksanakan untuk jangka waktu 3 minggu ke depan. Evaluasi akhir dilakukan dengan mengundang pakar pendidikan yang paham materi pembelajaran di Paud.
Pserta melakukan perbaikan dengan menerima masukan bersifat konstruktif. .

\section{HASIL DAN PEMBAHASAN}

Pelaksanaan pengabdian pada masyarakat di Satuan Paud Sejenis (SPS) Gandaria yang berdasarkan prioritas masalah yang disepakati (Tim pengusul PKM dengan Himpaudi dan Satuan Gugus Paud) dan khususnya SPS Gandaria bahwa solusi untuk menjaga keberlanjutan peningkatan kompetensi guru yang berdaya saing tinggi akan dilakukan melalui strategi peningkatan kemampuan pedagogik guru dengan pelatihan literasi digital. Maka pelaksanaan pelatihan dilaksanakan di dua tempat berbeda : pertama dilaksanakan di Laboratorium Komputer Comstract Fakultas MIPA Universitas Pakuan dan kedua di SPS Gandaria.

Tabel 1. Kegiatan Pelatihan IPTEKS

\begin{tabular}{|c|c|c|}
\hline No. & Uraian Kegiatan & Capaian Luaran \\
\hline 1. & $\begin{array}{l}\text { Pelatihan Uji Kompetensi } \\
\text { Guru (UKG) Online }\end{array}$ & $\begin{array}{l}\text { - Guru mampu mengakses dan mengisi soal Uji } \\
\text { Kompetensi Guru Online. } \\
\text { - Sertifikat Pelatihan UKG online ditandatangani } \\
\text { oleh Ketua Tim PKM. }\end{array}$ \\
\hline 2. & $\begin{array}{l}\text { Pelatihan pengisian dan } \\
\text { sinkronisasi dapodik online. }\end{array}$ & $\begin{array}{l}\text { - Guru mampu mengakses dan mengisi soal Uji } \\
\text { Kompetensi Guru Online. }\end{array}$ \\
\hline & & 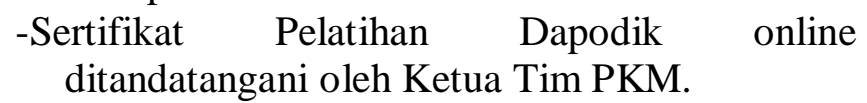 \\
\hline 3. & $\begin{array}{l}\text { Pelatihan pengisian borang } \\
\text { akreditasi Paud } \\
\text { (Sispena Borang) Online }\end{array}$ & $\begin{array}{l}\text { - Guru mampu mengakses dan mengisi Sispena } \\
\text { Borang Online } \\
\text { - Sertifikat Pelatihan Sispena Borang yang } \\
\text { ditandatangani oleh Ketua Tim PKM. }\end{array}$ \\
\hline 4. & $\begin{array}{l}\text { Pelatihan Pembuatan Desain } \\
\text { Media } \quad \text { Pembelajaran } \\
\text { Multimedia }\end{array}$ & $\begin{array}{l}\text { - Guru mampu mengakses dan membuat desain } \\
\text { pembelajaran multimedia } \\
\text { - Sertifikat Pelatihan Desain Pembelajaran } \\
\text { Multimedia yang ditandatangani oleh Ketua } \\
\text { Tim PKM. }\end{array}$ \\
\hline
\end{tabular}


DIFUSI

Volume 2, No.2 Juli 2019

Kegiatan pelatihan dilaksanakan secara bertahap dan disesuaikan dengan waktu guru-guru SPS Gandaria dan dibagai dalam empat tahapan seperti terlihat pada Tabel 4.

Materi pelatihan dikemas dalam bentuk buku ber-ISBN memuat modul keempat pelatihan tersebut ditambah lagi dengan modul MS-Word, MS-Excel dan Power Point. Guru perlu memahami pengetahuan dasar tentang software komputer MS-Word untuk dapat membuat surat, tabel dan isian dalam Sispena Borang. MS-Excel diperlukan untuk dapat membuat tabel-tabel data tenaga pendidik dan data siswa dalam mengisi Dapodik Online. Power Point diperlukan untuk membuat desain pembelajaran multi media, membuat video, memotong video dan lain sebagainya.

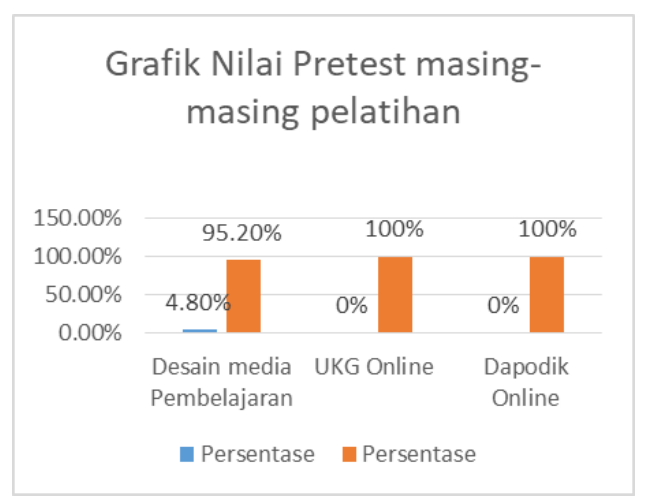

Gambar 1. Grafik Hasil Pre Test

Untuk melihat pencapaian hasil IPTEKS yang didesiminasikan kepada para peserta guru SPS Gandaria, maka diberikan soal Pre Test dan Post Test. Adapun hasil yang diperoleh ditunjukkan dari grafik di bawah ini. Pada awalnya kompetensi pedagogik tentang literasi digital sangat rendah 4,80\% dan bahkan nol. Artinya guru belum mampu mengakses dan mengerjakan soal-soal Uji Kompetensi Guru Online, memahami Dapodik Online, Sispena Borang dan membuat desain pembelajaran multimedia. Guru yang mengikuti pelatihan ada 7 orang dan hanya 2 orang saja yang baru memahami literasi digital, 5 orang lainnya belum mampu mengoperasikan komputer. Berikut di bawah ini gambar hasil Pre Test.

Setelah mengikuti pelatihan IPTEKS dengan 4 ketrampilan yang didesiminasikan, terlihat ada pencapaian kompetensi pedagogik literasi digital guru dengan rerata untuk Uji Komptensi Guru Online 34\%, Dapodik dan Sispena Borang $45 \%$ dan desain pembelajaran sekitar 28\%. Berdasarkan grafik tersebut disimpulkan bahwa tingkat kesulitan pelatihan tertinggi terletak pada pelatihan membuat desain pembelajaran multi media. Sedangkan Dapodik Online mudah diakses dan dipahami tetapi pembuatan MS-Excel nya sangat sulit dan perlu pelatihan lanjutan. Berikut adalah gambar 2 . grafik dari hasil Post Test yang menunjukkan pencapaian hasil pelatihan.

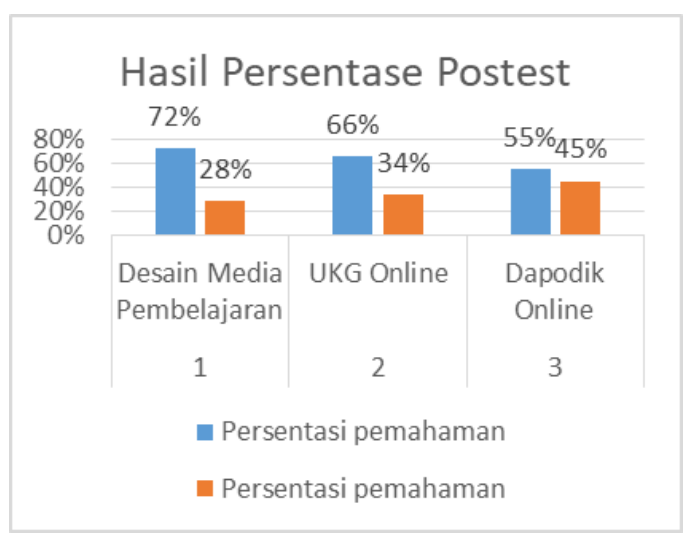

Gambar 2. Grafik Hasil Post Test 

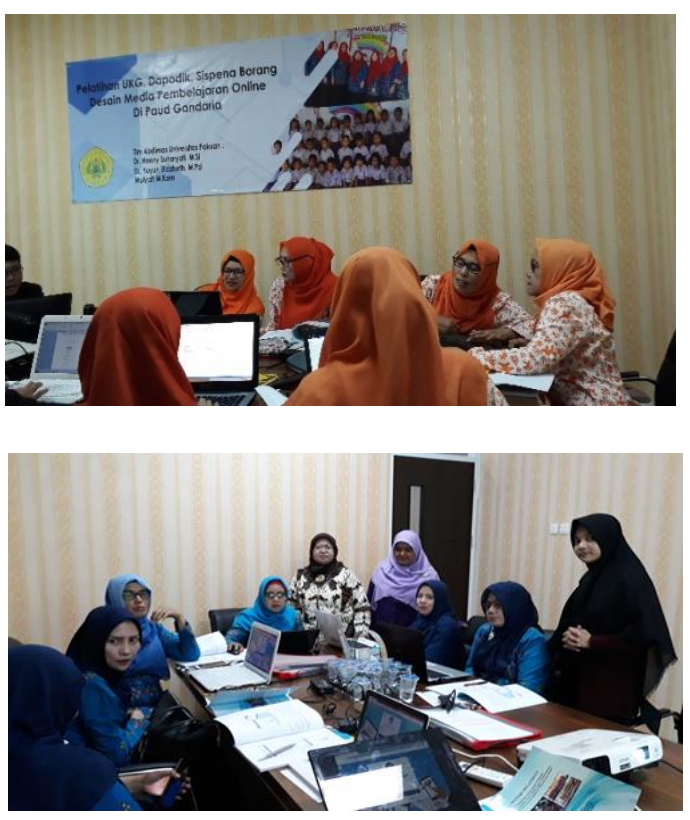

Gambar 3. Kegiatan Pelatihan

Semua materi pelatihan tersebut dikemas dalam bentuk buku dan juga dibuat dalam produk Kompilasi Data yang disimpan dalam Website Satuan Paud Sejenis (SPS) Gandaria. Hal ini dilakukan untuk menjaga sustaining responsibility dari pelatihan yang didesiminasikan. Adapun kegiatan pelatihan dapat dilihat pada Gambar 3.

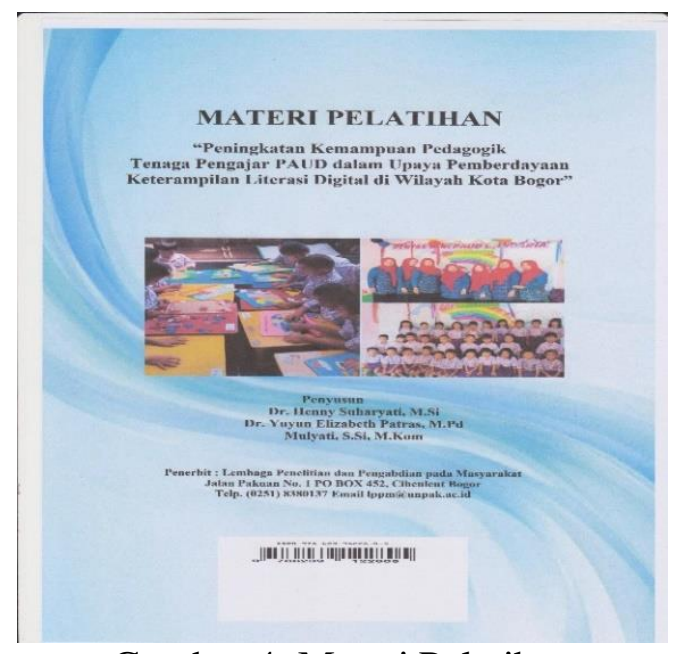

Gambar 4. Materi Pelatihan

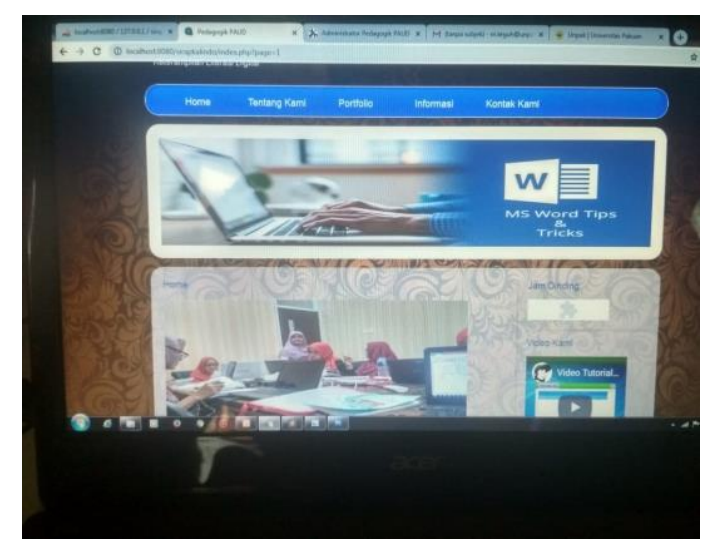

Gambar 5. Website SPS Gandaria

\section{KESIMPULAN}

Dampak pelaksanaan pembinaan kegiatan pelatihan dan diseminasi IPTEKS tersebut di atas dirasakan sangat bermanfaaat bagi guru-guru SPS Gandaria yang memiliki latar belakang awal sebagai ibu rumah tangga yang gagap teknologi menjadi melek literasi digital. Guru-guru SPS Gandaria menjadi lebih percaya diri dalam mengakses data dalam bentuk digital dan menggunakannya untuk membuat bahan ajar multimedia dan menyampaikan materi kepada siswa/siswinya.

Berdasarkan solusi dan target luaran yang direncanakan yaitu ada 4 tahapan: 1) Pelatihan UKG Online, 2) Pelatihan Dapodik Online, 3) Pelatihan Sispena Borang akreditasi, 4) Pelatihan pembuatan desain pembelajaran multi media yang kreatif dan inovatif. Pelatihan dapat terlaksana dengan baik tetapi pencapaian masih jauh dibawah target, dengan demikian perlu dilakukan pelatihan yang berkelanjutan. 


\section{UCAPAN TERIMA KASIH}

Pengabdian pada masyarakat ini dilaksanakan atas dana dari Hibah DRPM Kemenristekdikti pada tahun pelaksanaan 2019 berdasarkan Surat Perjanjian Penugasan Nomor: 108/SPP2H/PPM/DRPM/2019 Tanggal 8 Maret 2019. Dengan demikian kami ucapkan terimakasih kepada Kemenristekdikti yang sudah mendanai dengan surat perjanjian pendanaan antara Kantor L2Dikti4 dengan Universitas Pakuan Nomor: 2842/ L4 / PP / 2019 Tanggal 21 Maret 2019.

\section{REFERENSI}

[1] Suharyati, Henny, 2016, Relationship between Organizational Culture, Transformational Leadership, Working Motivation to Teacher's Innovativeness, International Journal on Managerial Studies Research, Vol.4, No. 3, p. 29-34.

[2] Azan, Khairun, Tantangan Pendi dikan di Era Globalisasi, https://www.kompasiana.com/khair ulazan130320/59dc880e3f8bf43be4 2512e2/tantangan-pendidikan-diera-globalisasi, diunduh tgl 5 Oktober 2018.

[3] Rindaningsih, Ida. 2012. Pengembangan Model Manajemen Strategik Berbasis (Beyond Center and Circle Time) BCCT Pada PAUD. PEDAGOGIA. Vol. 1, No. 2, Hal. 213-223.

[4] Sigit, Bambang. Joko. 2008. Pengembangan Pembelajaran dengan Menggunakan Multimedia Interaktif untuk Pembelajaran yang Berkualitas Semarang. Karya Tulis Ilmiah. Universitas Negeri Semarang.

[5] Suheri, Agus. 2006. Animasi Multimedia Pembelajaran. Jurnal Informatika Volume 2-No.1 : Periode Juli Desember 2006

[6] Sutopo, Hadi, A., 2003, Multimedia Interaktif dengan Flash. Graha Ilmu, Yogyakarta. 